\title{
A study on sublabial transsphenoidal treatment of pituitary tumor under microscope with aid of endoscope
}

\author{
Yunchol Pak ${ }^{*}$, Xuejun Yang ${ }^{2}$, Yongdok Kim, Chanhong Jong ${ }^{1}$, Haksong Kim, Namhyok Lee ${ }^{1}$, Songgun Kim \\ and Yongchol Kim ${ }^{1}$
}

\begin{abstract}
Background: A pituitary tumor is a tumor with a high incidence among brain tumors. Microscopic traditional STT approach with aid of endoscope has a high therapeutic effect and few complications.

Methods: The authors reviewed 146 patients who underwent STT resection of sellar masses between January 1 , 2006, and December 31, 2013. From this group, 40 patients who underwent microscopic STT surgery with aid of endoscope were included in the study. In this series, there were many nonfunctional and Growth Hormone(GH) secreting adenoma. In the study group, tumor size ranged from 60 to $79 \mathrm{~mm}$ in 3 cases. Pathophysiological studies, tumor sizes, clinical outcomes, extent of resection, visual function and complication were estimated.

Results: In our study, gross-total resection(GTR) was achieved in 33 patients (82.5\%), subtotal in 3 (7.5\%), and partial in 4 (10\%). Visual acuity were improved in $82.1 \%$, while $17.9 \%$ were unchanged. Visual fields were improved in $81.2 \%$. No deaths occurred in this cohort of patients.

Conclusions: Pituitary adenoma surgery under microscope with aid of endoscope is an effective treatment method, which results in high $(>90 \%)$ rates of resection. It is not associated with high rates of major complications and is safe when performed by experienced surgeons.
\end{abstract}

Keywords: STT approach, Endoscopic, Sellar, Pituitary surgery, Complication

\section{Background}

Pituitary adenomas comprise about $10-12 \%$ of all intracranial tumors [1]. The microscopic STT approach has been recognized as a less-invasive surgery for pituitary tumors [2,3]. Endoscopic endonasal pituitary tumor surgery provides a more clear and panoramic view and made it possible to distinguish the boundary between the tumor, the cavernous sinus and the arachnoid membrane [4-10]. However, postoperative CSF leak and some infectious complications has not disappeared and has become a frequent complication [11-17]. Nasal septum bone flap is reported to very effective for restoration of dural defect in sellar area after tumor removal [18-22]. We describe

\footnotetext{
* Correspondence: pakyunchol@163.com

${ }^{1}$ Department of Neurosurgery, Pyongyang Medical School Hospital, Kim II Sung General University, Pyongyang, Democratic People's Republic of Korea Full list of author information is available at the end of the article
}

a method of obtaining a bone flap necessary for the sellar floor repairment using the traditional STT approach, and exploring and remove a residual tumor with a endoscope, which simply not visible with microscope [23].

\section{Method}

Patient materials

This study was approved by the Neurosurgery Clinic of Pyongyang medical school hospital of the Kim Il Sung General University in DPRK. One hundred forty-five consecutive patients of pituitary adenomas treated between January 2006 and December 2013 with or/not endoscopic removal were retrospectively reviewed. All patients were treated by the same neurosurgeons. The patients, whose follow-up period was over one year, were 65 men and 81 women, with ages ranging from 20 to 65 years old (mean 46.6). 
Among the 116 pituitary adenomas, 39 were growth hormone-secreting, 10 were prolactin-secreting, 3 were adrenocorticotropic hormone-secreting and 61 were nonfunctioning adenomas (Table 1). All 52 functioning adenomas were microadenomas and the others were macroadenomas (Table 1, Fig. 1). Eight patients had undergone previous surgeries, including transsphenoidal surgery in five patients, craniotomy in two patients, and both in one patient.

Data collected included observation of intraoperative CSF fistula, and postoperative complications including CSF fistula, meningitis and septal perforation.

\section{Surgical technique}

The patient is placed in supine position and have been administered general anesthesia. The surgeon stands on the right side of the patient and elevates the head of the operating table by 15 degrees and tilts the face about 30 degrees to the left. The gingivobuccal sulcus, septum and face skin around the mouth was sterile and draped. Then,the gingivobuccal sulcus and nasal septum were infiltrated with lidocaine hydrochloride $(\mathrm{HCl})$ and $1 / 200000$ adrenaline. A horizontal sublabial incision was made to the depth of the periosteum of the maxilla, which was elevated superiorly to the pyriform aperture, the anterior nasal spine and the anterior angle of the nasal septum.

The anterior edge of the cartilaginous nasal septum was incised by a blade, and the mucous membrane was peeled from the cartilaginous and the osseous nasal septum by using a peeler so that it opened the mucosa sideways. The cartilaginous nasal septum was peeled to the right for repairment later. The Hardy speculum was inserted and the nasal mucosa of the deep part was separated from the deep osseous nasal septum. Bone nasal septum flap were reserved for restoration of sellar floor after the main procedure. Make sure that both blade of the Hardy speculum are placed symmetrically in the midline (Fig. 2a). Next, using the surgical microscope found the natural ostium of the sphenoidal sinus, and removed the sphenoidal bones with a punch(Fig. 2b).

Table 1 Pathology

\begin{tabular}{lllllll}
\hline Group & $\begin{array}{l}\text { Non- } \\
\text { functioning }\end{array}$ & GH & Prolactin & ACTH & Mixed & Etc \\
\hline $\begin{array}{l}\text { Control } \\
(n=105)\end{array}$ & $45(42.9)$ & $25(23.8)$ & $5(4.8)$ & $2(1.9)$ & $3(2.8)$ & $25(23.8)$ \\
$\begin{array}{l}\text { Study } \\
(n=40)\end{array}$ & $16(40.0)$ & $14(35.0)$ & $5(12.5)$ & $1(2.5)$ & & $4(10.0)$ \\
\hline
\end{tabular}

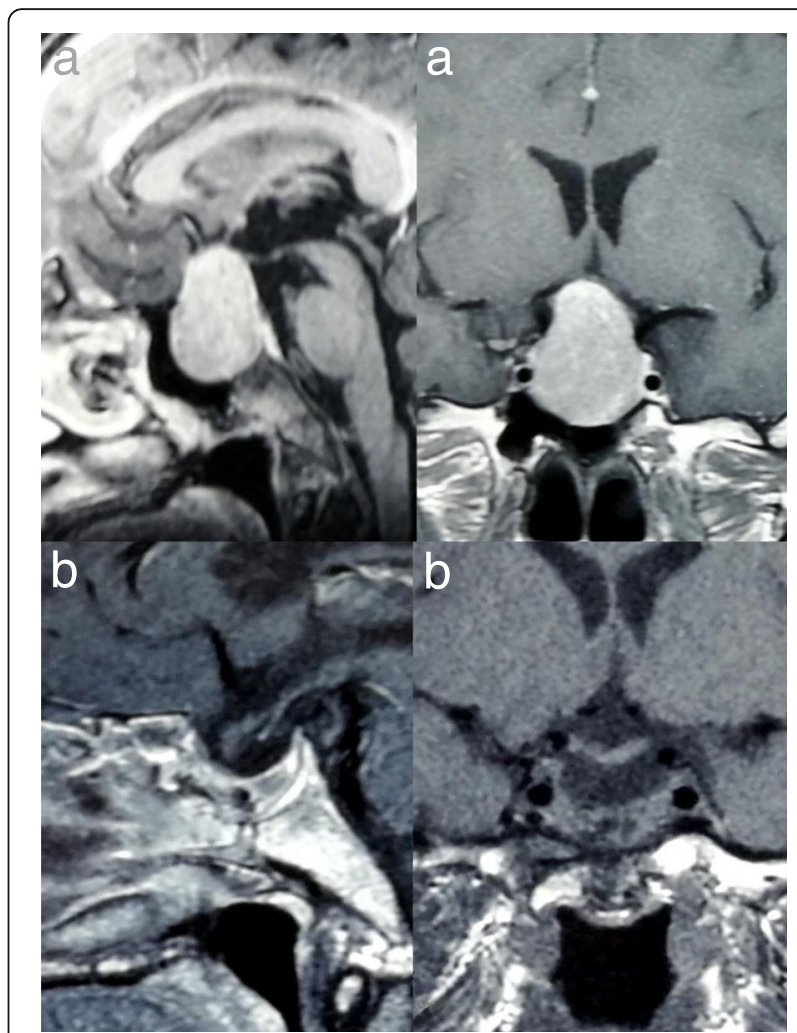

Fig. 1 Coronal and sagittal MRI images of a patient who underwent a STT approach a. MRI image before surgery, showing a large pituitary adenoma extending suprasellar area and compressing the optic chiasm upward, b. MRI image 6 month later STT surgery showing fat grafts in the sella turcica and sphenoid sinus. The diaphragm sellae has descended into the sellar cavity and revealed complete disappearance of the tumor in the sellar and suprasellar region

If there was an interstitial wall within the sphenoidal sinus, it will also be removed to reach the sellar floor using rongeur and a fine chisel (Fig. 2c). The dura was revealed (Fig. 2d). The test puncturing is performed with an injector of long needle to check whether or not there is a cyst or an aneurysm, and the sellar dura was dissected (Fig. 2e). The tumor was removed using suction and various types of ring curette (Fig. 2f).

Although the tumor is small, the lesion was re-examined and the residual tumor was removed under the endoscopic view. If the tumor is large and cannot be found under the microscope, using an $30^{\circ}$ and $75^{\circ}$ endoscope searched and removed the residual tumor. The fascia that was harvested from the lateral femur was filled in the sellar space and restored to the bony nasal septum which was remained for the repairment of sellar defect [24]. The cartilaginous nasal septum was restored to the midline and the nasal mucosa was returned to its original position. Nasal 

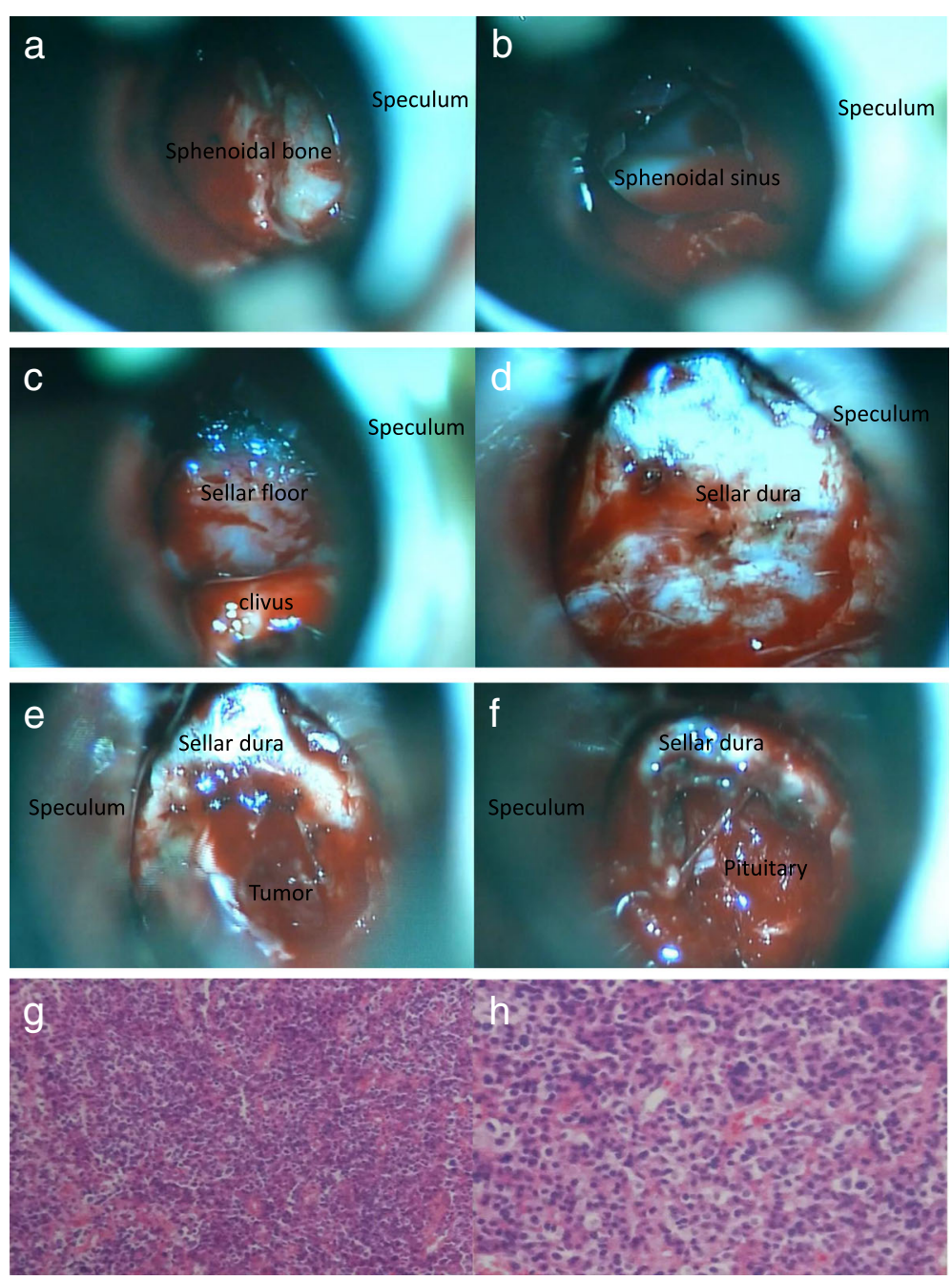

Fig. 2 Removal of the tumor and pathological studies. a: Insertion of Hardy speculum to the sphenoidal bone. $\mathbf{b}$ : Confirm of ostium of sphenoidal sinus and removal of sphenoidal bone. c: Confirm of sellar floor. $\mathbf{d}$ : Removal of sphenoidal floor and exposure of sellar dura. e: The sellar dura was opened with a cruciate incision. f: Image after tumor removal. g, h: Pathological studies: multifunctional adenoma; $\mathrm{PRL}(+), \mathrm{GH}(+), \mathrm{TSH}(++)(\mathbf{g}$ : hematoxylin and eosin staining, original magnification, ${ }^{*} 200$. $\mathbf{h}$ : hematoxylin and eosin staining, original magnification, ${ }^{*} 400$ )

cavity was filled with gauze of ointment to fix the nasal mucosa and inserted the air tube to allowed to nasal breathing. Finally, sutured gingivobuccal mucosa. The filling material was removed 3 days after surgery.

\section{Evaluation method}

\section{Pathology}

In this series, pituitary adenomas were classified according to immunohistochemical staining patterns

Table 2 Size of tumor

\begin{tabular}{lllllllll}
\hline Group & $\sim 9$ & $10 \sim 19$ & $20 \sim 29$ & $30 \sim 39$ & $40 \sim 49$ & $50 \sim 59$ & $60 \sim 69$ & $70 \sim 79$ \\
\hline $\begin{array}{l}\text { Control } \\
(n=106)\end{array}$ & $8(7.5)$ & $12(11.3)$ & $54(50.9)$ & $26(24.5)$ & $4(3.8)$ & $2(1.9)$ & & \\
$\begin{array}{l}\text { Study } \\
(n=40)\end{array}$ & $1(2.5)$ & $5(12.5)$ & $8(20.0)$ & $17(42.5)$ & $5(12.5)$ & $1(2.5)$ & $1(2.5)$ & $2(5.0)$ \\
\hline
\end{tabular}

[25]. In the study group, the number of nonfunctioning(40.0\%) and GH adenoma(35.0\%) was large and the number of nonfunctioning adenoma(42.9\%) was large in the control group (Fig. 2g, h, Table 1).

\section{Size of tumor}

All patients underwent contrast - enhanced computed tomography(CT) and/or magnetic resonance imaging(MRI)

Table 3 Tumor removal grade

\begin{tabular}{llll}
\hline Group & $\begin{array}{l}\text { Total } \\
\text { removal }\end{array}$ & $\begin{array}{l}\text { Subtotal } \\
\text { removal }\end{array}$ & $\begin{array}{l}\text { Partial } \\
\text { removal }\end{array}$ \\
\hline Control $(n=106)$ & $75(70.8)$ & $16(15.1)$ & $15(14.1)$ \\
Study $(=40)$ & $33(82.5)^{* *}$ & $3(7.5)$ & $4(10.0)$ \\
\hline$* *(p<0.01)$ & & &
\end{tabular}


Table 4 Change of visual acuity

\begin{tabular}{lll}
\hline Group & $\begin{array}{l}\text { The number of } \\
\text { defected eye } \\
\text { Before surgery }\end{array}$ & $\begin{array}{l}\text { The number of } \\
\text { improved eye } \\
\text { After surgery }\end{array}$ \\
\hline Control $(n=212)$ & $138(100.0)$ & $112(81.1)$ \\
Study $(n=80)$ & $56(100.0)$ & $46(82.1)$ \\
\hline
\end{tabular}

$\mathrm{n}$ : The number of eye

before surgery. The tumor size was defined as the greatest diameter of lesion on MRI. In the study group, the number of 30 to $39 \mathrm{~mm}$ size(42.5\%) was large and the number of 20 to $29 \mathrm{~mm}(50.9 \%)$ was large in the control group (Fig. 1a, Table 2).

\section{Tumor removal}

Two surgical technique, including the traditional microscopic STT approach(72.6\%) and microscopic STT approach with aid of endoscope(27.4\%) were utilized to remove the sellar tumors.

The extent of tumor removal was assessed by MRI after 6 months to confirm the survival of the tumor (Fig. 1b, Table 3).

\section{Change of visual function}

We compared the preoperative and postoperative 7th day's visual acuity and visual field tests to determine the treatment effect (Tables 4 and 5).

\section{Statistical method}

Chi Square Test and Fisher's Exact Test was used. A $p$ value $<0.05$ was considered significant difference.

\section{Result}

As shown in Table 3, in the study group, GTR was archived in 33 patients $(82.5 \%)$ and in the control group was 75 patients(70.8\%). There was no significant difference in visual function improvement between the two groups (Tables 4 and 5).

Table 5 Change of visual field

\begin{tabular}{lll}
\hline Group & $\begin{array}{l}\text { The number of } \\
\text { defected eye } \\
\text { Before surgery }\end{array}$ & $\begin{array}{l}\text { The number of } \\
\text { improved eye } \\
\text { After surgery }\end{array}$ \\
\hline Control $(n=212)$ & $144(100.0)$ & $116(80.5)$ \\
Study $(n=80)$ & $64(100.0)$ & $52(81.2)$ \\
\hline
\end{tabular}

$\mathrm{n}:$ The numberof eye
Table 6 Therapy efficiency

\begin{tabular}{lllllll}
\hline Group & Cure & Good & No change & Worse & Death & Efficacy (\%) \\
\hline $\begin{array}{l}\text { Control } \\
(n=106)\end{array}$ & $78(73.6)$ & $20(18.9)$ & $5(4.7)$ & $1(0.9)$ & $2(1.9)$ & 92.5 \\
$\begin{array}{l}\text { Study } \\
(n=40)\end{array}$ & $35(87.5)$ & $4(10.0)$ & $1(2.5)$ & & & $97.5^{*}$ \\
\hline$*(p<0.05)$ & & & & & & \\
\hline
\end{tabular}

\section{Surgical outcomes}

Treatment efficacy was significantly higher in the study group $(97.5 \%)$ than in the control group $(92.5 \%)$ (Table 6).

\section{Postoperative complication}

As shown in Table 7, postoperative complication was recognized in the control group and there were no complications in the study group. The patients with postoperative complications in the control group were reoperation patients.

\section{Discussion}

Since the end of the 2000s, we have begun surgery on pituitary tumors by combination of endoscopes with traditional STT approach. With aid of overseas Korean, we achieved the part of rigid endoscope, light source and air drill. Based on this, using the $0^{\circ}, 30^{\circ}$ and $75^{\circ}$ endoscope we have decided to remove residual tumor which couldnot be removed with traditional STT approach and adopted it into practice [26].

As a result of applying this method to surgery, the treatment was more effective. Although fully endoscopic endonasal surgery regards to minimally invasive method to the patients and has a higher treatment efficacy, there are still some issues to be solved in many aspects such as postoperative CSF rhinorrhea and infection. In addition, dural substitute and fibrin glue etc. used in endoscopic surgery were all imported, so it did not fit our situation [27].

Therefore, we tried to improve the tumor removal efficiency by combining endoscopes of various angles with traditional STT approach. As shown in the results of the study, the operative efficiency was high and the postoperative complications such as CSF leakage and meningitis were still few $[14,15,28-30]$.

Table 7 Postoperative complication

\begin{tabular}{llll}
\hline Group & Rhinorrhea & Meningitis & $\begin{array}{l}\text { Septal } \\
\text { perforation }\end{array}$ \\
\hline Control $(n=106)$ & $1(0.94)$ & $1(0.94)$ & $1(0.94)$ \\
Study $(=40)$ & $0(0.0)$ & $0(0.0)$ & $0(0.0)$ \\
\hline
\end{tabular}




\section{Conclusion}

STT surgery to the pituitary tumor combined with endoscope is still a significant surgical procedure. Especially postoperative complications are extremely low. It is a very economical surgical approach that allows you to achieve great success with a little cost. It is also helpful to extract a tumor that can not be seen under a microscope.

\section{Abbreviations}

ACTH: Adrenocorticotrophic hormone; CSF: Cerebrospinal fluid; CT: Computed tomography; DPRK: Democratic people's republic of korea; GH: Growth hormone; GTR: Gross total resection; $\mathrm{HCl}$ : Hydrochloride; MRI: Magnetic resonance imaging; PA: Pituitary adenoma; ST: Sublabial transseptal transsphenoida

\section{Acknowledgements}

We would like to thank Dr. Jianhua Xiong Department of Neurosurgery, General Hospital, Tianjin Medical University,Tianjin,China, for his suggestion in preparing this article.

\section{Funding}

Not applicable.

\section{Availability of data and materials}

The authors declare that the data supporting the findings of this study are available within the article.

\section{Author's contributions}

YP, XY and Yongdok Kim reviewed the patient records from hospital, participated in drafted the manuscript. HK participated in the design of the study. NL and SK conceived of the study, and participated in its design and coordination and CJ and Yongchol Kim helped to draft the manuscript. All authors read and approved the final manuscript.

\section{Ethics approval and consent to participate}

Not applicable.

\section{Consent for publication}

Not applicable.

\section{Competing interests}

The authors declare that they have no competing interests.

\section{Author details}

${ }^{1}$ Department of Neurosurgery, Pyongyang Medical School Hospital, Kim II Sung General University, Pyongyang, Democratic People's Republic of Korea. 2Department of Neurosurgery, General Hospital, Tianjin Medical University, Tianjin, China.

Received: 9 April 2018 Accepted: 5 July 2018

Published online: 03 September 2018

\section{References}

1. Oruckaptan HH, Senmevsim O, Ozcan OE, et al. Pituitary adenomas: results of 684 surgically treated patients and review of the literature. Surg Neurol. 2000;53:211-9.

2. Dallapiazza R, Bond AE, Grober $Y$, Louis RG, Payne SC, Oldfield EH, Jane JA Jr. Retrospective analysis of a concurrent series of microscopic versus endoscopic transsphenoidal surgeries for Knosp grades 0-2 nonfunctioning pituitary macroadenomas at a single institution. J Neurosurg. 2014;121:511-7.

3. Gao Y, Zhong C, Wang Y, Xu S, Guo Y, Dai C, Zheng Y, Wang Y, Luo Q, Jiang J. Endoscopic versus microscopic transsphenoidal pituitary adenoma surgery: a meta-analysis. World J Surg Oncol. 2014;12:94.

4. Dhandapani S, Singh H, Negm HM, Cohen S, Anand VK, Schwartz TH. Cavernous sinus invasion in pituitary adenomas: systematic review and pooled data meta-analysis of radiologic criteria and comparison of endoscopic and microscopic surgery. World Neurosurg. 2016;96:36-46.
5. Elhadi AM, Hardesty DA, Zaidi HA, Kalani MY, Nakaji P, White WL, Preul MC, Little AS. Evaluation of surgical freedom for microscopic and endoscopic transsphenoidal approaches to the Sella. Neurosurgery. 2015; 11(Suppl 2):69-78.

6. Jane JA Jr, Dumont AS, Sheehan JP, Laws ER Jr. Inactive Adenomas. In: Tonn J-C, Westphal M, Rutka JT, Grossman SA, editors. Neuro-oncology of CNS tumors. United States of America: Springer; 2006. p. 184.

7. Juraschka K, Khan OH, Godoy BL, Monsalves E, Kilian A, Krischek B, Ghare A, Vescan A, Gentili F, Zadeh G. Endoscopic endonasal transsphenoidal approach to large and giant pituitary adenomas: institutional experience and predictors of extent of resection. J Neurosurg. 2014:121:75-83.

8. Singh H, Essayed WI, Cohen-Gadol A, Zada G, Schwartz TH. Resection of pituitary tumors: endoscopic versus microscopic. J Neuro-Oncol. 2016;130: 309-17

9. Wagenmakers MA, Boogaarts HD, Roerink SH, Timmers HJ, Stikkelbroeck NM, Smit JW, van Lindert EJ, Netea-Maier RT, Grotenhuis JA, Hermus AR. Endoscopic transsphenoidal pituitary surgery: a good and safe primary treatment option for Cushing's disease, even in case of macroadenomas or invasive adenomas. Eur J Endocrinol. 2013;169:329-37.

10. Zoli M, Milanese L, Bonfatti R, Sturiale C, Pasquini E, Frank G, Mazzatenta D. Cavernous sinus invasion by pituitary adenomas: role of endoscopic endonasal surgery. J Neurosurg Sci. 2016;60:485-94.

11. Ammirati M, Wei L, Ciric I. Short-term outcome of endoscopic versus microscopic pituitary adenoma surgery: a systematic review and metaanalysis. J Neurol Neurosurg Psychiatry. 2013;84:843-9.

12. de Divitiis E, Laws ER, Giani U, Iuliano SL, de Divitiis O, Apuzzo ML. The current status of endos-copy in transsphenoidal surgery: an international survey. World Neurosurg. 2015:83:447-54.

13. Goudakos JK, Markou KD, Georgalas C. Endoscopic versus microscopic transsphenoidal pituitary surgery: a systematic review and meta-analysis. Clin Otolaryngol. 2011;36:212-20

14. Halvorsen H, Ramm-Pettersen J, Josefsen R, Rønning P, Reinlie S, Meling T, Berg-Johnsen J, Bollerslev J, Helseth E. Surgical complications after transsphenoidal microscopic and endoscopic surgery for pituitary adenoma: a consecutive series of 506 procedures. Acta Neurochir. 2014;156:441-9.

15. Magro E, Graillon T, Lassave J, Castinetti F, Boisson-neau S, Tabouret E, Fuentes S, Velly L, Gras R, Dufour H. Complications related to the endoscopic endonasal transsphenoidal approach for nonfunc-tioning pituitary macroadenomas in 300 consecutive patients. World Neurosurg. 2016;89: 442-53.

16. Mortini P. Cons: endoscopic endonasal transsphenoidal pituitary surgery is not superior to microscopic transsphenoidal surgery for pituitary adenomas. Endocrine 2014:47:415-20

17. Tabaee A, Anand VK, Brown SM, Lin JW, Schwartz TH. Algorithm for reconstruction after endoscopic pituitary and skull base surgery. Laryngoscope Database. 2007; https://doi.org/10.1097/MLG.0b013e31805c08c5

18. Cappabianca P, Cavallo LM, Esposito F, Valente V, Divitiis E. Sellar repair in endoscopic endonasal transsphenoidal surgery: results of 170 cases. Neurosurgery Database. 2002; https://doi.org/10.1227/01.NEU.0000309112. 17087.28

19. Esposito F, Dusick JR, Fatemi N, Kelly DF. Graded repair of cranial base defects and cerebrospinal fluid leaks in transsphenoidal surgery. Operative Neurosurgery Database. 2007; https://doi.org/10.1227/01.NEU.0000255354. 64077.66

20. Romero AC, Nora JE, Topczewski TE, Aguiar PH, Alobid I, Rodriquéz EF. Cerebrospinal fluid fistula after endoscopic transsphenoidal surgery: experience in a spanish center. SciELO Database. 2010; https://doi.org/ $10.1590 / 50004-282 \times 2010000300017$

21. Sciarretta V, Mazzatenta D, Ciarpaglini R, Pasquini E, Farneti G, Frank G. Surgical repair of persisting CSF leaks following standard or extended endoscopic transsphenoidal surgery for pituitary tumor. Thieme Database. 2010; https://doi.org/10.1055/s-0029-1246161

22. Zanation AM, Carrau RL, Snyderman CH, Germanwala AV, Gardner PA Prevedello DM, et al. Nasoseptal flap reconstruction of high flow intraoperative cerebral spinal fluid leaks during endoscopic skull base surgery. Ingenta Database. 2009; https://doi.org/10.2500/ajra.2009.23.3378

23. Jho HD, Carrau RL. Endoscopy assisted transsphenoidal surgery for pituitary adenoma. Technical note. Acta Neurochirurgica. 1996:138(12):1416-25.

24. Uygur ER, et al. Sublabial Transseptal Approach to Pituitary Adenomas with Special Emphasis on Rhinological Complications. Turkish Neurosurgery. 2008;18(4):425-30 
25. McCutcheon IE. Pituitary tumors in oncology. In: DeMonte F, Gilbert MR, Mahajan A, McCutcheon IE, editors. Tumors of the brain and spine. United States of America: Springer; 2007. p. 193-4.

26. Kerr PB, Oldfield EH. Sublabial-endonasal approach to the Sella turcica. J Neurosurg. 2008;109(1):153-5.

27. Levi $V$, et al. Microscopic versus endoscopic transsphenoidal surgery for pituitary adenoma: analysis of surgical safety in 221 consecutive patients. John Wiley \& Sons Ltd _ Clinical Otolaryngology. 2016;42: 439-94.

28. Spencer WR, Levine JM, Couldwell WT, et al. Approaches to the sellar and parasellar region: a retrospective comparison of the endonasal-transsphenoidal and sublabial-transsphenoidal approaches. Otolaryngol Head Neck Surg. 2000; 122(3):367-9.

29. Urquhart AC, Bersalona FB, Ejercito VS, et al. Nasal septum after sublabial transseptal transsphenoidal pituitary surgery. Otolaryngol Head Neck Surg. 1996;115(1):64-9.

30. Zaidi HA, Awad AW, Bohl MA, Chapple K, Knecht L, Jahnke H, White WL, Little AS. Comparison of outcomes between a less experienced surgeon using a fully endoscopic technique and a very experienced surgeon using a microscopic transsphenoidal technique for pituitary adenoma. J Neurosurg. 2016;124:596-604

Ready to submit your research? Choose BMC and benefit from:

- fast, convenient online submission

- thorough peer review by experienced researchers in your field

- rapid publication on acceptance

- support for research data, including large and complex data types

- gold Open Access which fosters wider collaboration and increased citations

- maximum visibility for your research: over $100 \mathrm{M}$ website views per year

At BMC, research is always in progress.

Learn more biomedcentral.com/submissions 